\title{
$\mathrm{MoS}_{2}$ Nanosheets-Cyanobacteria Interaction:
}

\section{Reprogrammed Carbon and Nitrogen Metabolism}

\author{
Si Chen ${ }^{1}$, Nibin Shi ${ }^{1}$, Min Huang ${ }^{1}$, Xianjun $\operatorname{Tan}^{2}$, Xin Yan ${ }^{1}$, Aodi Wang ${ }^{1}$, Yuxiong \\ Huang $^{2}$, Rong Ji ${ }^{1}$, Dongmei Zhou ${ }^{1}$, Yong-Guan Zhu ${ }^{3}$, Arturo A. Keller ${ }^{4}$, Jorge L. Gardea- \\ Torresdey $^{5}$, Jason C. White ${ }^{6}$, Lijuan Zhao ${ }^{1 *}$
}

${ }^{1}$ State Key Laboratory of Pollution Control and Resource Reuse, School of Environment, Nanjing University, Nanjing 210023, China

${ }^{2}$ Shenzhen Environmental Science and New Energy Technology Engineering Laboratory, Tsinghua-Berkeley Shenzhen Institute (TBSI), Tsinghua Shenzhen International Graduate School, Tsinghua University, Shenzhen 518055, China

${ }^{3}$ Key Laboratory of Urban Environment and Health, Institute of Urban Environment, Chinese Academy of Sciences, Xiamen 361021, China

${ }^{4}$ Chemistry and Biochemistry Department, The University of Texas at El Paso, 500 West University Avenue, El Paso, Texas 79968, United States

${ }^{5}$ Bren School of Environmental Science \& Management and Center for Environmental Implications of Nanotechnology, University of California, Santa Barbara, California 93106, United States

${ }^{6}$ The Connecticut Agricultural Experiment Station (CAES), New Haven, Connecticut 06504, United States

Si Chen, Nibin Shi, and Min Huang contribute equally to this work

*Corresponding author. Email: 1jzhao@nju.edu.cn 


\section{This supplementary material includes:}

Page S3-S4 Supporting Information for Method

\section{Page S5 Table S1}

Page S6-S13 Figure S1 to S8 


\section{Supporting Information for Method}

CAT-like Activity of $\mathrm{MoS}_{\mathbf{2}}$ Nanosheets. The CAT-like activity of $\mathrm{MoS}_{2}$ nanosheets was investigated using fluorescence spectroscopy. Terephthalic acid (TPA) can react with $\cdot \mathrm{OH}$, that can be decomposed by $\mathrm{H}_{2} \mathrm{O}$, to generate fluorescent 2-hydroxy-terphthalic acid (TPA-2-OH), with excitation/emission peaks are 315/425 $\mathrm{nm}$ respectively. In the presence of CAT (or CAT analogue), $\mathrm{H}_{2} \mathrm{O}_{2}$ degrades into $\mathrm{H}_{2} \mathrm{O}$ and $\mathrm{O}_{2}$, and fluorescent TPA-2-OH cannot be formed. Therefore, we investigated the CAT-like activity of $\mathrm{MoS}_{2}$ nanosheets by monitoring the fluorescence signal of TPA-2-OH. Briefly, $\mathrm{H}_{2} \mathrm{O}_{2}(10 \mathrm{mM})$ and different concentrations of $1 \mathrm{~T}$ and $2 \mathrm{H} \mathrm{MoS}$ nanosheets $(1,10,100 \mathrm{mg} / \mathrm{L})$ were added into the phosphate buffer (PBS, $10 \mathrm{mM}, \mathrm{pH} 7.4$ ) and incubated at $40{ }^{\circ} \mathrm{C}$ for $5 \mathrm{~h}$. Then, TPA in $\mathrm{NaOH}(2 \mathrm{mM})$ was added. After mixing the resultant solution, fluorescence spectrum of the mixture was measured.

SOD-like Activity of $\mathrm{MoS}_{\mathbf{2}}$ Nanosheets. The SOD-like activity of $\mathrm{MoS}_{2}$ Nanosheets was investigated by formazan formation using a (2-(4 iodophenyl)-3-(4 nitrophenyl)-5-(2,4disulfophenyl)-2H-tetrazolium (WST-1) assay kit (Nanjing Jiancheng Bioengineering Institute, Nanjing, China). Xanthine oxidase (XO) oxidizes xanthine to produce $\mathrm{O}_{2}^{-}$, which can react with WST-1 to form WST-1 formazan. The inhibition rate of $\mathrm{MoS}_{2}$ nanosheets to $\mathrm{O}_{2}^{-}$was calculated by monitoring the absorbance of formazan concentration at $450 \mathrm{~nm}$.

POD-like Activity of $\mathrm{MoS}_{\mathbf{2}}$ Nanosheets. The POD-like activity of $\mathrm{MoS}_{2}$ nanosheets was 
determined using 3,3,5,5-tetramethylbenzidine (TMB) as the substrate. Typically, $100 \mu \mathrm{L}$ of TMB $(10 \mathrm{mg} / \mathrm{mL}), 233 \mu \mathrm{L}$ of $\mathrm{H}_{2} \mathrm{O}_{2}(30 \%$ (wt/vol)) and different concentrations $1 \mathrm{~T}$ and $2 \mathrm{H} \mathrm{MoS}$ nanosheets $(1,10$ and $100 \mathrm{mg} / \mathrm{L})$ were added into $1.8 \mathrm{~mL}$ of acetate buffer solution $(\mathrm{NaAc}, 0.2 \mathrm{M}, \mathrm{pH}=4.5)$ at room temperature. The absorbance changes of the reaction system at $652 \mathrm{~nm}$ within $10 \mathrm{~min}$ were detected using a microplate spectrophotometer (Synergy H4 Hybrid Reader, BioTek, America). 
Table S1. The composition of BG11-N growth medium

\begin{tabular}{|c|c|}
\hline Component & Concentration (mM) \\
\hline $\mathrm{K}_{2} \mathrm{HPO}_{4}$ & 0.22 \\
\hline $\mathrm{MgSO}_{4} \cdot 7 \mathrm{H}_{2} \mathrm{O}$ & 0.03 \\
\hline $\mathrm{CaCl}_{2} \cdot 2 \mathrm{H}_{2} \mathrm{O}$ & 0.24 \\
\hline Citric Acid $\cdot \mathrm{H}_{2} \mathrm{O}$ & 0.012 \\
\hline Ferric Ammonium Citrate & 0.02 \\
\hline $\mathrm{Na}_{2}$ EDTA $2 \mathrm{H}_{2} \mathrm{O}$ & 0.002 \\
\hline $\mathrm{Na}_{2} \mathrm{CO}_{3}$ & 0.18 \\
\hline Sodium Thiosulfate Pentahydrate & 1 \\
\hline $\mathrm{H}_{3} \mathrm{BO}_{3}$ & 46 \\
\hline $\mathrm{MnCl}_{2} \cdot 4 \mathrm{H}_{2} \mathrm{O}$ & 9 \\
\hline $\mathrm{ZnSO}_{4} \cdot 7 \mathrm{H}_{2} \mathrm{O}$ & 0.77 \\
\hline $\mathrm{Na}_{2} \mathrm{MoO}_{4} \cdot 2 \mathrm{H}_{2} \mathrm{O}$ & 1.6 \\
\hline $\mathrm{CuSO}_{4} \cdot 5 \mathrm{H}_{2} \mathrm{O}$ & 0.3 \\
\hline $\mathrm{Co}\left(\mathrm{NO}_{3}\right)_{2} \cdot 6 \mathrm{H}_{2} \mathrm{O}$ & 0.17 \\
\hline
\end{tabular}




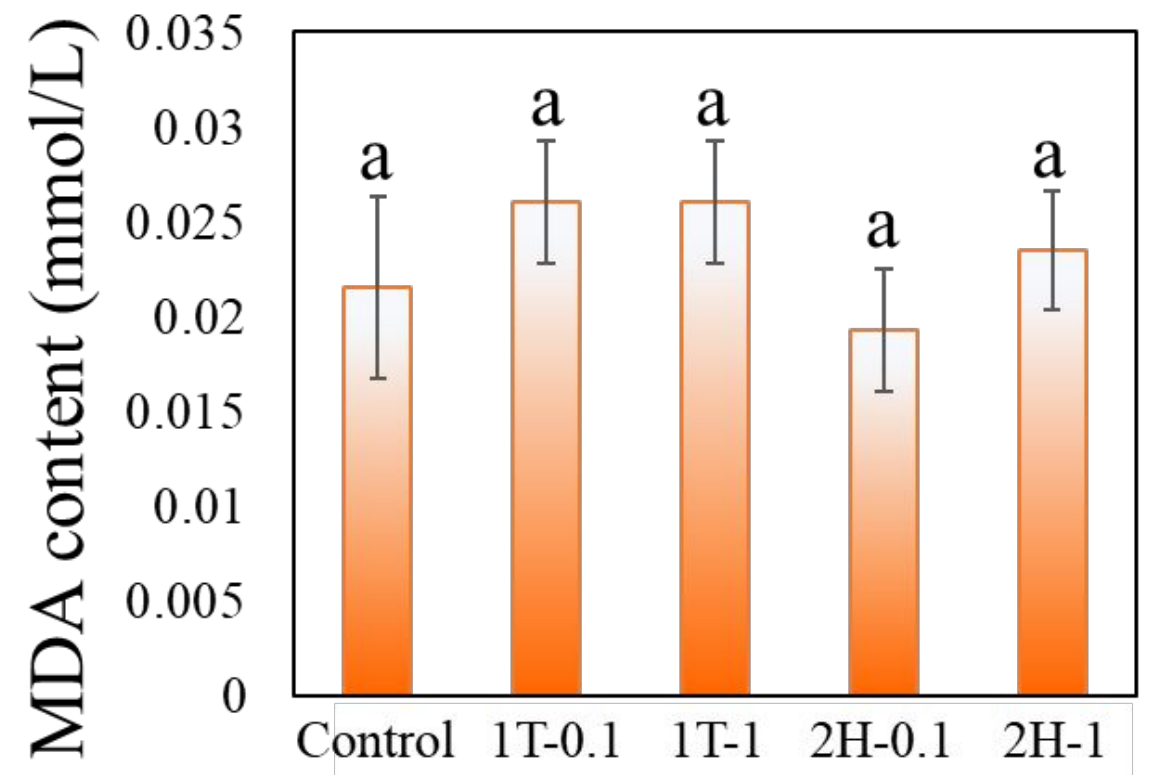

Figure S1. MDA content of Nostoc exposed to $0,0.1$, and $1 \mathrm{mg} / \mathrm{L}$ of $1 \mathrm{~T}$ or $2 \mathrm{H} \mathrm{MoS}_{2}$ nanosheets for $96 \mathrm{~h}$. Data are means of 4 replicates. Error bars represent standard deviation. 


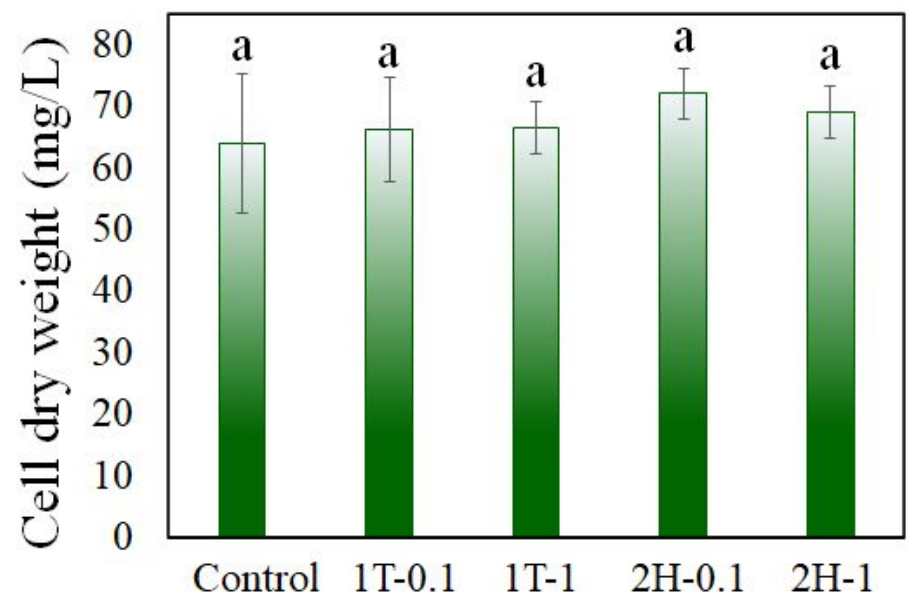

Figure S2. Effects of MoS2 exposure on the dry weight of Nostoc. Data are means of 4 replicates. Error bars represent standard deviation. 

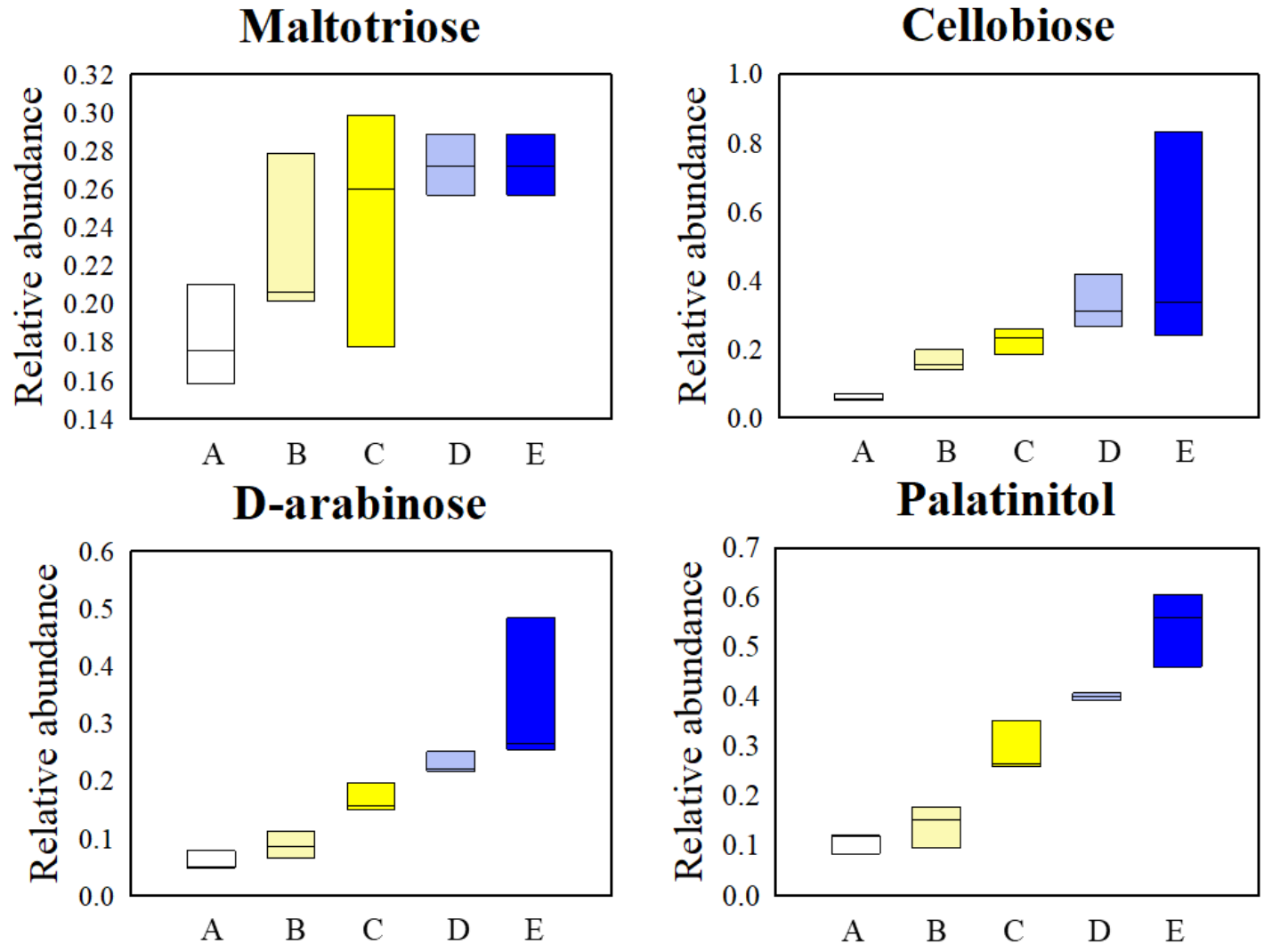

Figure S3. Relative abundance of significantly increased carbohydrates in Nostoc. A, B, C, D, E represent control, $1 \mathrm{~T} \mathrm{MoS}_{2}$ at $0.1 \mathrm{mg} / \mathrm{L}, 1 \mathrm{~T} \mathrm{MoS}_{2}$ at $1 \mathrm{mg} / \mathrm{L}, 2 \mathrm{H} \mathrm{MoS}$ at 0.1 $\mathrm{mg} / \mathrm{L}, 2 \mathrm{H} \mathrm{MoS}$ at $1 \mathrm{mg} / \mathrm{L}$, respectively. 

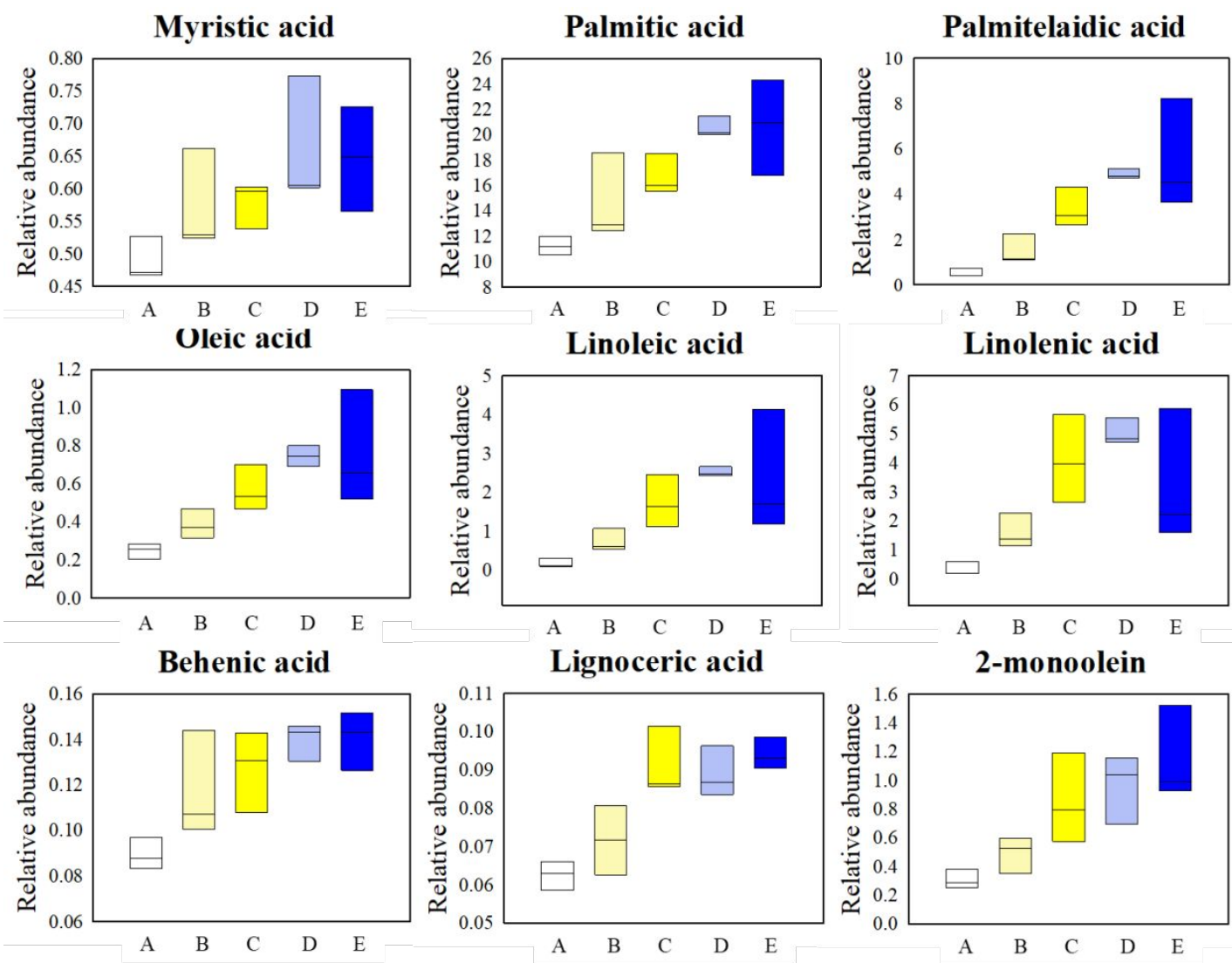

Figure S4. Relative abundance of significantly increased fatty acids in Nostoc. A, B, C, D, E represent control, $1 \mathrm{~T} \mathrm{MoS}_{2}$ at $0.1 \mathrm{mg} / \mathrm{L}, 1 \mathrm{~T} \mathrm{MoS}_{2}$ at $1 \mathrm{mg} / \mathrm{L}, 2 \mathrm{H} \mathrm{MoS}$ at $0.1 \mathrm{mg} / \mathrm{L}$, $2 \mathrm{H} \mathrm{MoS}_{2}$ at $1 \mathrm{mg} / \mathrm{L}$, respectively. 
(r)-3- hydroxybutyric acid

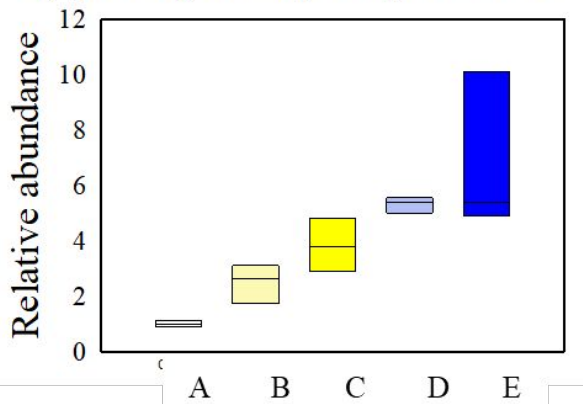

D-myo-inositol 4-phosphate

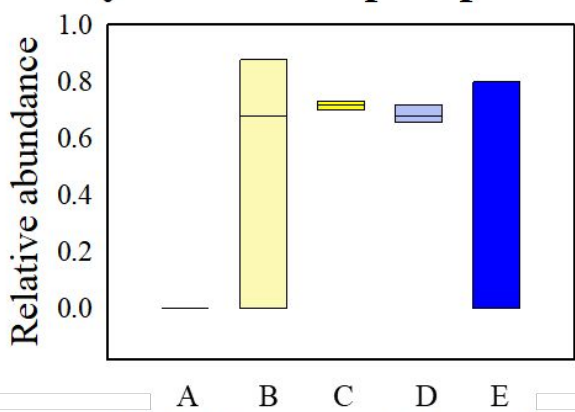

Dehydroascorbic acid
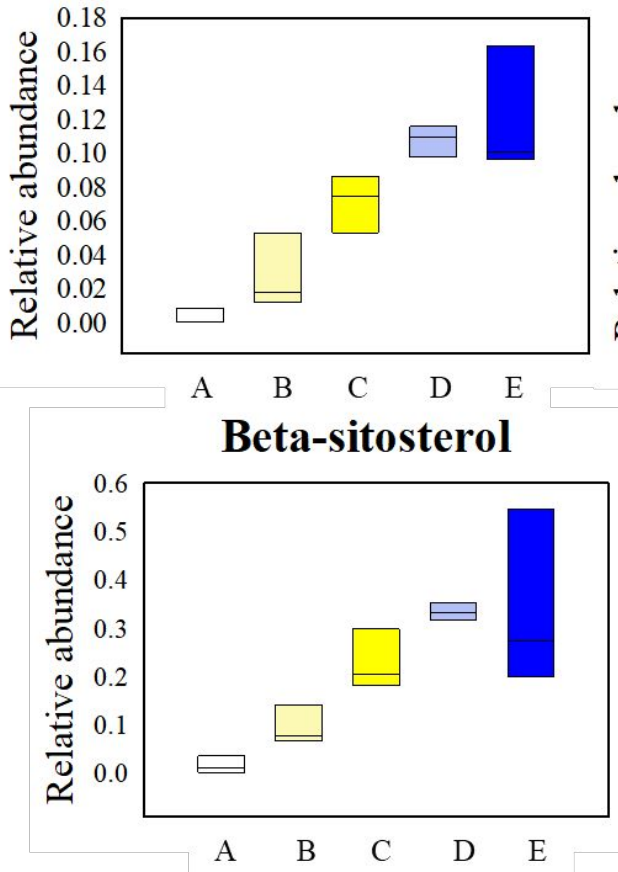

Myo-inositol

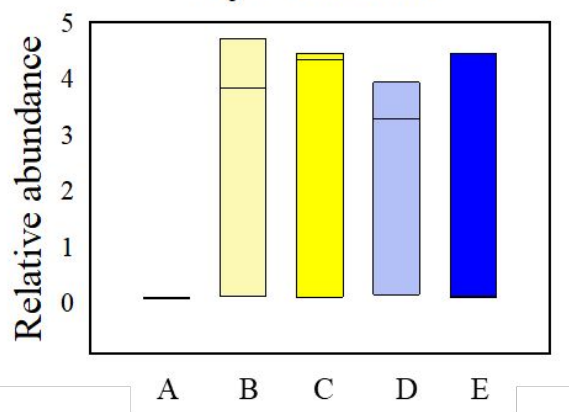

Glucosamine

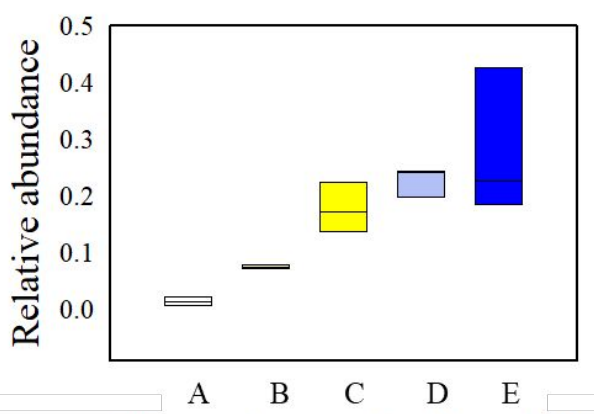

Chenodeoxycholic acid

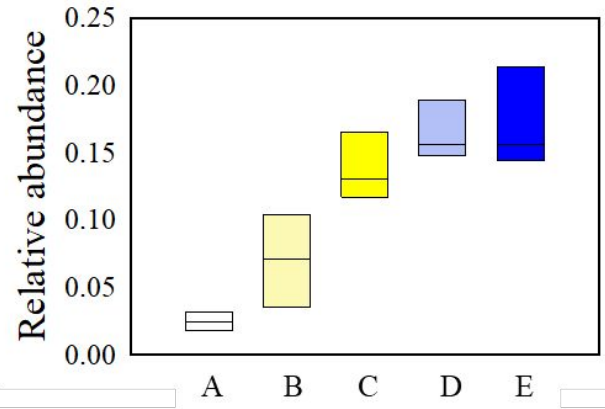

Formononetin

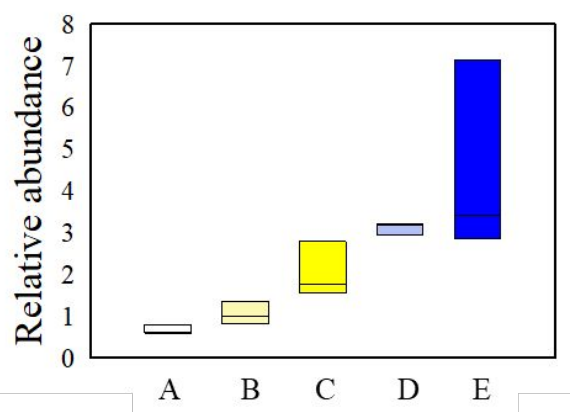

Figure S5. Relative abundance of significantly increased valuable biochemicals in Nostoc. A, B, C, D, E represent control, $1 \mathrm{~T} \mathrm{MoS}_{2}$ at $0.1 \mathrm{mg} / \mathrm{L}, 1 \mathrm{~T} \mathrm{MoS} \mathrm{S}_{2}$ at $1 \mathrm{mg} / \mathrm{L}, 2 \mathrm{H}$ $\mathrm{MoS}_{2}$ at $0.1 \mathrm{mg} / \mathrm{L}, 2 \mathrm{H} \mathrm{MoS}_{2}$ at $1 \mathrm{mg} / \mathrm{L}$. 


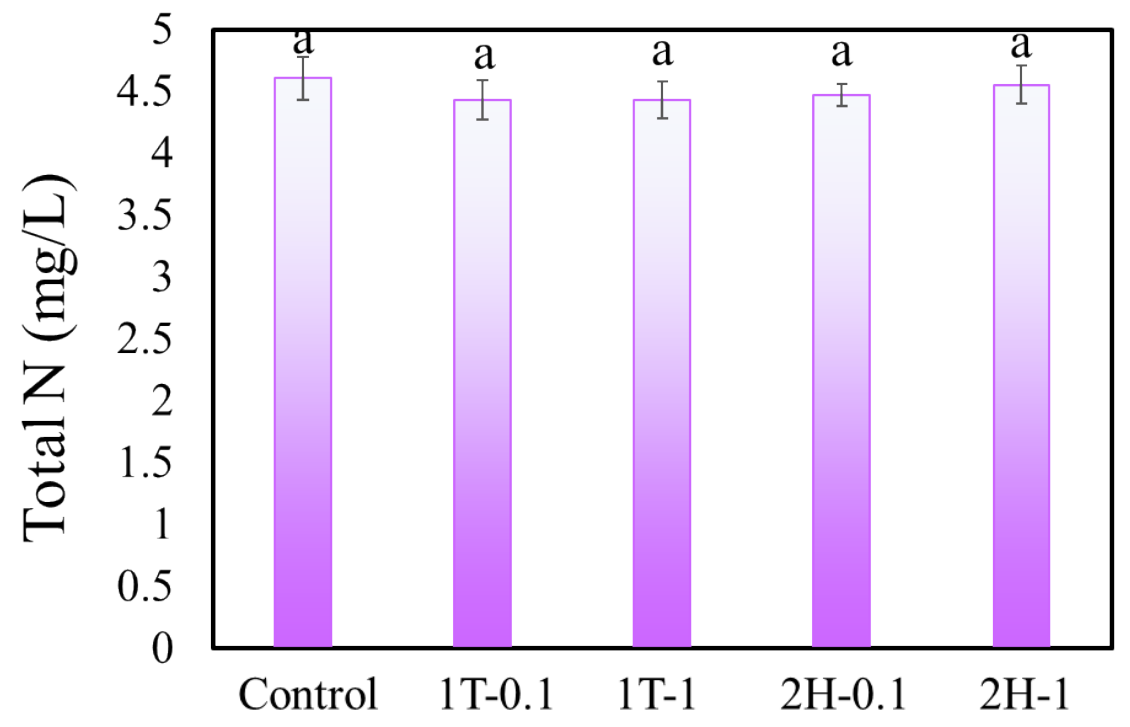

Figure S6. Total nitrogen content of Nostoc exposed to $0,0.1$, and $1 \mathrm{mg} / \mathrm{L}$ of $1 \mathrm{~T}$ or $2 \mathrm{H}$ $\mathrm{MoS}_{2}$ nanosheets for $96 \mathrm{~h}$. Data are means of 4 replicates. Error bars represent standard deviation. 

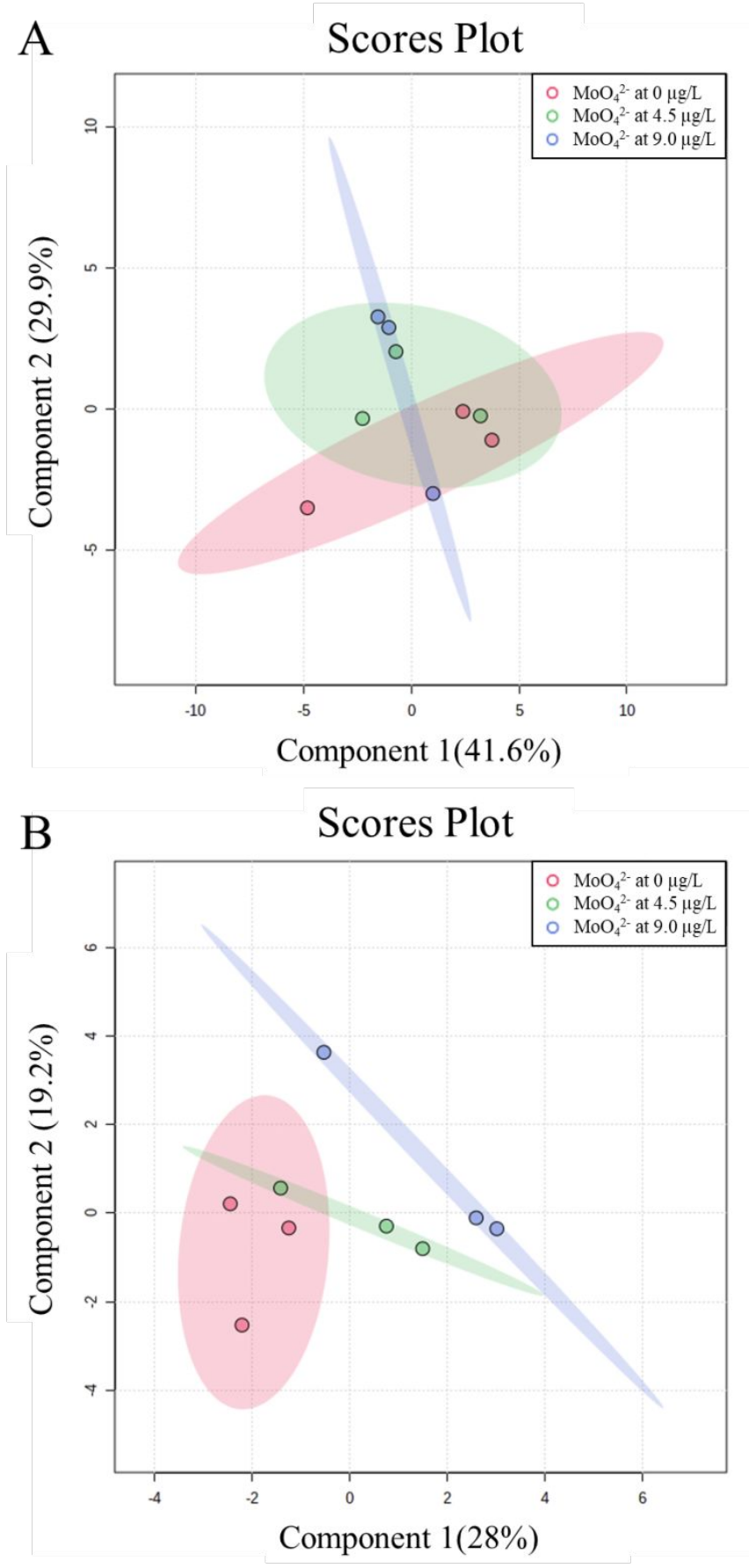

Figure S7. Principal Component Analysis (PCA) score plots (A) and partial least-squares discriminant (PLS-DA) scores plot (B) of metabolic profiles in Nostoc treated without and with different concentrations of Mo ions $\left(\mathrm{Na}_{2} \mathrm{MoO}_{4} 2 \mathrm{H}_{2} \mathrm{O}\right)$ at 4.5 and $9 \mu \mathrm{g} / \mathrm{L}$. 


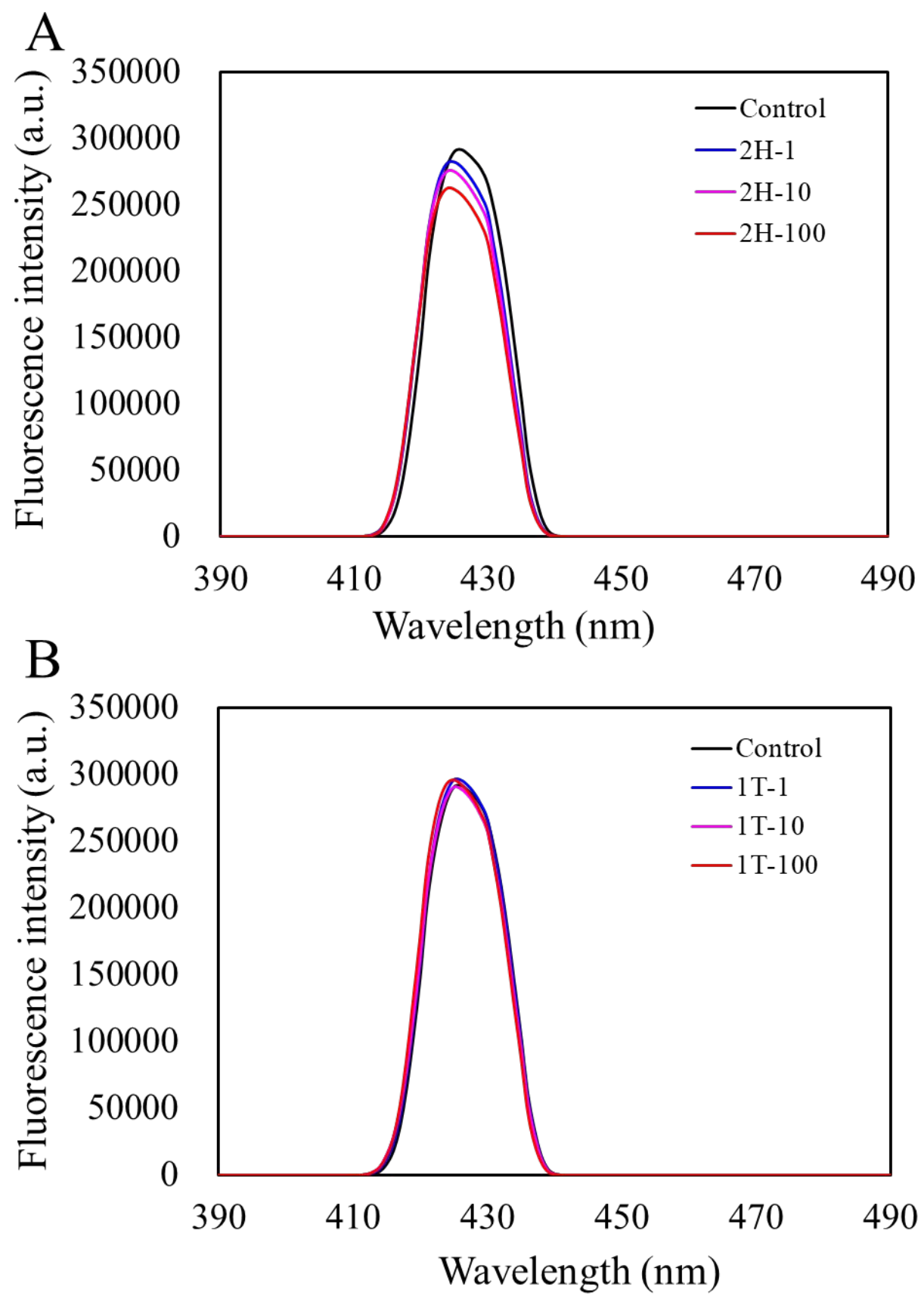

Figure S8. The CAT-like activities of $\mathrm{MoS}_{2}$ nanosheets. Fluorescence spectra for interaction of TPA with $\mathrm{H}_{2} \mathrm{O}_{2}$ and different concentrations of $1 \mathrm{~T}$ and $2 \mathrm{H} \mathrm{MoS}_{2}$ nanosheets $(1,10$ and $100 \mathrm{mg} / \mathrm{L})$. 